\title{
Crop mixtures outperform rotations and landscape mosaics in regulation of wheat pathogens: a simulation study
}

Pierre-Antoine Précigout ( $\nabla$ pierre-antoine.precigout@inrae.fr )

INRAE UMR ECOSYS https://orcid.org/0000-0001-6195-4076

Delphine Renard

CEFE: Centre d'Ecologie Fonctionnelle et Evolutive

Jonathan Sanner

CERES, Ecole Normale Superieure

David Claessen

CERES, Ecole Normale Superieure

Corinne Robert

INRAE UMR ECOSYS

\section{Research Article}

Keywords: crop diversity, crop mixtures, crop rotation, landscape mosaic, biocontrol, mathematical modelling

Posted Date: March 1st, 2022

DOI: https://doi.org/10.21203/rs.3.rs-1324974/v1

License: (c) (i) This work is licensed under a Creative Commons Attribution 4.0 International License. Read Full License 


\section{Abstract}

Context. Strategies of crop diversification such as crop rotations, within-field mixtures and landscape mosaics including susceptible and resistant crops can limit crop epidemics. Until now, the effects of these strategies have been studied separately, on single pathogen species, and with low environmental variability.

Objectives. In this paper, we aim to compare the disease-limitation effect of these three crop diversification strategies on two highly damaging pathogens of wheat Puccinia recondita and Zymoseptoria tritici and under varying weather conditions.

Methods. We built a dynamic mathematical model of epidemics at the field scale (based on classical Susceptible-Exposed-Infectious-Removed epidemiological models) embedded in a spatially explicit landscape grid framework. We use it to simulate an agricultural landscape in which diversification strategies translate into different proportions of wheat and resistant crops in the landscape.

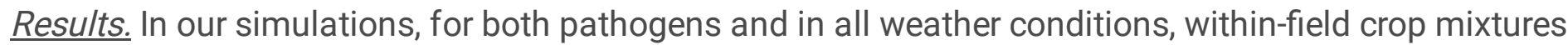
had the greatest impact in limiting epidemics, crop rotations were second-best, while landscape mosaics were the least effective. We also found a threshold in the proportion of wheat in mixtures below which increase in the proportion of resistant plants does not lead to further disease limitation. However, a higher proportion of resistant crop was needed when the weather became favourable for the pathogens, suggesting that higher levels of diversification are needed to limit strong epidemics.

Conclusions. Our findings imply that interactions between spatial the scale of crop diversification strategies, pathogen characteristics and weather conditions should be considered in order to maximize benefits from disease-regulation properties of diversified cropping systems under climate change.

\section{Introduction}

Promoting crop diversity in agricultural systems is a promising strategy to sustainably regulate epidemics ecologically and limit harvest and economic losses (Barot et al. 2017). At the scale of a single field, sowing mixtures of susceptible and resistant crop varieties (Finckh et al. 2000; Mundt 2002; Newton 2009) or species (Mommer et al. 2018) can reduce fungal epidemics up to 70-80\% (Kolster et al. 1989; Finckh et al. 1999). At the landscape scale, crops arranged in a mosaic of resistant and susceptible fields side by side also hamper pathogen development (Burdon et al. 2014; Papaïx et al. 2014a, b; Rimbaud et al. 2018b). Along with crop diversification strategies across space, diversification can also be managed through time. In the same field, rotation of different crops in successive years has long been known for its role in preventing the build-up of pathogen (Hossard et al. 2018; Bargués-Ribera and Gokhale 2020).

Until now, most studies evaluating the ecological benefits of crop diversification focused on one practice at a time (Beillouin et al. 2019), one pathogen at a time, and in one given environment. We found only one study comparing the effects of within-field crop mixtures, landscape mosaics and rotations on the 
regulation of wheat rust (Rimbaud et al. 2018a). Yet, that study focused on the effect of diversification on the speed of pathogen breakdown of crop resistance and therefore put little emphasis on the ecological regulation conferred by crop diversification strategies. While multiple pathogen traits (including latent period, dispersal mode, interculture survival and overwintering) and environmental conditions (weather in particular) all modulate the pathogen's response to crop diversification practices (McDonald and Linde 2002; Robert et al. 2008; Fabre et al. 2015), past research limitation to one practice or one pathogen at a time did not account for the complexity arising from the interactions between functional traits of pathogens, weather conditions and diversification practices (Nicholls and Altieri 2004).

In this study, we simulate the impact of three different crop diversification strategies deployed across spatial and temporal scales on two pathogen species under various seasonal weather conditions. We focus on two pathogens with contrasted traits and contrasted responses to weather conditions (Robert et

al. 2005; Garin et al. 2014) that are highly damaging pathogenic fungi of wheat: wheat leaf rust (hereafter WLR) and Septoria tritici blotch (hereafter STB). We developed a dynamic mathematical model of epidemics at the within-field scale (based on Susceptible-Exposed-Infectious-Removed, SEIR model (Gilligan 2008), embedded in a spatially explicit landscape grid framework (Papaïx et al. 2014a; Rimbaud et al. 2018a; Le Gal et al. 2020) where crop fields in the landscape are linked through pathogen dispersal. The model is original in its ability to simulate spatial scales from the field to the landscape and temporal scales from a daily rainfall event, to a crop season and then to several years of cultivation and to simulate different foliar fungal pathogens with different infection cycle traits and responses to climate.

\section{Methods}

In this section, we first present some biological features of the two pathogens that we deemed necessary to understand our modelling choices. We then describe the implementation of the model before finally presenting the simulation scenarios.

\section{Wheat leaf rust and septoria tritici blotch}

Wheat leaf rust (Puccinia recondita f. sp. tritici, hereafter WLR) and Septoria tritici blotch (Zymoseptoria tritici, hereafter STB) share biological features common to many leaf pathogenic fungi (van Maanen and Xu 2003; Caubel et al. 2012; Garin et al. 2014). In particular, they cause polycyclic diseases: spores that fall on leaves of susceptible plants germinate and infect the leaf where they create new lesions. The time between infection and the onset of reproduction of lesions is called the latent period. At the end of this period, lesions become mature and start releasing spores. Spores disperse and can initiate new lesions on the same leaf, on other leaves of the same plant or on the leaves of new susceptible hosts nearby (in the field or further). The number of infection cycles determines the intensity of the annual epidemic.

Based on previously published comparisons between WLR and STB (Robert et al. 2005; Garin et al. 2014), we considered four main differences between their life cycles that may lead to contrasted responses to crop diversification and weather variables: (i) duration of the latent period, (ii) dispersal ability (dispersal 
mode and range), (iii) start date of the epidemic depending on weather conditions, and (iv) trophic behaviour and associated capacity to survive the interculture. Trait differences are reflected by differences in parameter values in our model (Table 1). In this section we explain the four main differences considered and how we expressed these differences in our model.

First, STB has a longer latent period, and thus a longer infection cycle than WLR (Précigout et al. 2020a). The duration of an infection cycle, and the number of infection cycles during a cropping season, are key pathogen characteristics interacting with crop growth, determining the outcome of the crop-pathogen interaction and therefore the amount of damage caused by the pathogen (Robert et al. 2008, 2018; Précigout et al. 2017; Garin et al. 2018). This is why we aimed to incorporate this important aspect in our classical SEIR model by implementing an age structure of the lesions when they are latent (see Eqs. 2123 below). In doing so, we ensure that any amount of leaf surface newly infected will remain asymptomatic during a full latent period ( $\lambda$ parameter) before becoming infectious. To our knowledge, this is the first combination of a semi-continuous SEIR model and a discrete modelling of the latent period of the pathogen. The latent period of pathogenic fungi is particularly sensitive to temperature (Précigout et al. 2020a). This is why in our model, we chose to express both plant and pathogen development (and thus latent periods) in thermal time (degree-days, dd) (Robert et al. 2008, 2018; Garin et al. 2014; Précigout et al. 2017).

Second, STB asexual spores mainly disperse through raindrop splashes from infected leaves (Eyal 1987) while WLR asexual spores are mainly dispersed by wind (Sache 2000). Consequently, STB asexual spores disperse over shorter distances (up to one meter within a field (Saint-Jean et al. 2004)) while wind allows WLR asexual spores to disperse over short (within a field) and long (outside the field) distances (Sache 2000; Mundt et al. 2011). Furthermore, because the dispersal of STB asexual spores occurs only when rainfall is of sufficient intensity (Walklate 1989), dispersal events of STB are less frequent than those of WLR, for which dispersal takes place almost every day as long as air humidity is not too low (Duvivier et al. 2016). In a much lower proportion, STB also produces sexual spores dispersed by wind that can leave their native field. Their role in epidemic propagation was considered as low (Suffert and Sache 2011), but recent studies question their importance in particular for long distance dispersal, survival in dry weather and inoculum production. Suffert and Sache (2011) and Suffert et al. (2019) indeed showed that though usually rare, these long-distance dispersal events could be of significance since they can lead to the infection of neighboring fields. This is why in our model we consider both asexual and sexual spores for STB. This is an additional originality of our model. We modelled the specific spore dispersal characteristics via different dispersal types ( $d$ function, Eqq. 10 and 11), different maximum dispersal distances ( $\Delta$ parameter, Eq. 12 ) and different behaviours concerning dispersal outside the native field (a parameter, Eq. 10).

Third, in addition to the impact on dispersal, weather conditions also influence the onset of epidemics. In western Europe, winter wheat is sown in late October and STB epidemics start after seedling germination, when inoculum is splashed from the local crop residues (Suffert and Sache 2011; Morais et al. 2016). In our model, wheat seedlings can be infected from the first rainfall after plant germination if any inoculum 
is present in the field (as in Robert et al. $(2008,2018)$ and Baccar et al. $(2011))$. By contrast, WLR epidemics usually begin between late March (early epidemics, $800 \mathrm{dd}$ after sowing) and May (late epidemics, 1300 dd after sowing (El Jarroudi et al. 2014; Duvivier et al. 2016)). The date of the onset of the epidemic depends on weather conditions (weather should be warm enough) and also it requires the presence of an inoculum, which can be external or internal to the field (Sache 2000). Moreover, the date of the onset of the epidemic is known to determine the intensity of epidemics: the earlier they start, the more intense they are (Garin et al. 2018). In our model, this difference is reflected in the onset date $\left(k_{S}\right.$, Eq. 9$)$ of the epidemic that depends on the first rain for STB and that is set between March and May for WLR, reflecting different climatic spring conditions.

Fourth, STB is a hemibiotrophic pathogen that infects living tissue but kills the infected tissue to reproduce, while WLR is a biotrophic pathogen that needs living host tissue to live and reproduce (Perfect and Green 2001; Précigout et al. 2020a). This trophic characteristic has an impact on spore survival. STB can indeed survive the interculture and overwinter on dead crop residues (Suffert and Sache 2011), whereas WLR can only survive the interculture period in the presence of infected residual live plants or volunteer plants (Roelfs and Bushnell 1985; Eversmeyer and Kramer 1998). This difference is reflected in our model by a higher survival capacity during the interculture of STB ( $\theta$ parameter, Eq. 14).

\section{Model overview}

In our model, the landscape is a grid of $21 \times 21$ square fields. Fields are the elementary units of our model. Each field is planted with a resistant or susceptible crop, or a mixture of both. The resistant crop, which could be a resistant wheat cultivar or a different crop species, is assumed to be totally resistant to the disease. Both susceptible and resistant crops follow the same annual growth pattern. A year in the model corresponds to a crop growing season. We express both plant and pathogen growth in thermal time (degree-days, dd), facilitating the description of epidemics, whose development follows plant growth and its response to temperature. The disease dynamics, modelled at the field scale, correspond to a classical SEIR epidemiological model with inclusion of an age structure for the latent (E) compartment in order to model the pathogen's latent period as a discrete time period rather than a transmission rate between $\mathrm{E}$ and $\mathrm{I}$. The model keeps track of the number of spores released during each dispersal event, both within the field and outside the field. We consider different routes of infection depending on the type of inoculum. At the landscape scale, infected fields are linked together through pathogen dispersal. Table 1 gives the list of the model parameters along with their values and biological interpretation.

\section{Crop growth and seasonality of susceptible crops}

The healthy canopy of the susceptible crop is represented by its green leaf area index S ("susceptible" leaf area). Based on published empirical data (Hinzman et al. 1986; Benbi 1994; Forsman and Poutala 1997; Baccar et al. 2011; Huang et al. 2016), the wheat growth curve is simulated using a logistic model. $S$ increases from sowing $\left(k_{\text {init }}=0 \mathrm{dd}\right)$ to $k_{\text {growth }}=1400 \mathrm{dd}$, where $k$ represents the discrete time index within a year. After $k=k_{\text {growth }}$, Sbecomes senescent at a rate $\mu$ and is transformed into $R$ ("removed" 
leaf surface). Hence, in a healthy canopy, the total leaf area index at time $k$ is $L A I_{k}=S_{k}+R_{k}$. The dynamics of $S_{k}$ and $R_{k}$ are given by:

$$
S_{k+1}=S_{k}+g(k)-\mu S_{k} 1_{k \geq k_{\text {growth }}}(k)
$$

(Eq. 1)

with $g(k)$ being the growth rate of the crop corresponding to a logistic equation. $K$ represents the field carrying capacity (corresponding to the maximum value of the leaf area index) and $\beta$ the crop growth parameter of the logistic function.

$$
g(k)=\beta S_{k}\left(1-\frac{S_{k}}{K}\right) 1_{k<k_{\text {growth }}}(k)
$$

(Eq. 2)

and

$$
R_{k+1}=R_{k}+\mu S_{k} 1_{k \geq k_{\text {growth }}}(k)
$$

(Eq. 3)

Note that in the following,

$$
1_{\text {condition }}(k)=\left\{\begin{array}{c}
1 \text { when the condition is fulfilled } \\
\text { 0otherwise }
\end{array}\right.
$$

\section{Disease dynamics}

SEIR dynamics. Fields planted with susceptible crop display SEIR epidemiological dynamics. In the following, $S, E$, I and $R$ denote the surface (in square meters per square meter of ground, LAl unit) of healthy, latent, sporulating and senescent (removed) plant tissue, respectively. Susceptible tissue becomes exposed at a rate $c(k)$. Exposed tissue becomes infectious at a rate $h(k)$. As time goes on and spore dispersal occurs, older sporulating structures get progressively empty at a rate $\psi(k)$. Natural senescence affects all parts of the canopy at the same rate $\mu$. The dynamics of the different leaf compartments can thus be given by:

$$
S_{k+1}=S_{k}+g(k)-c(k) S_{k}-\mu S_{k} 1_{k \geq k_{\text {growth }}}(k)
$$

(Eq. 4)

$$
E_{k+1}=E_{k}+c(k) S_{k}-h(k)-\mu E_{k} 1_{k \geq k_{\text {growth }}}(k)
$$




$$
I_{k+1}=I_{k}+h(k)-\psi(k) I_{k}-\mu I_{k} 1_{k \geq k_{\text {growth }}}(k)
$$

(Eq. 6)

$$
R_{k+1}=R_{k}+\psi(k) I_{k}+\mu\left(S_{k}+E_{k}+I_{k}\right) 1_{k \geq k_{\text {growth }}}(k)
$$

(Eq. 7)

$$
L A I_{k}=S_{k}+E_{k}+I_{k}+R_{k}
$$

(Eq. 8)

where $g(k)$ is the crop growth rate introduced in Eqs. 1 and 2 and $L A I_{k}$ corresponds to the total leaf area index of the field canopy. The functions $c(k), h(k)$ and $\psi(k)$ depend on the pathogen species and the dynamics of the disease in the neighbouring fields, especially the production of inoculum (spores), and will be explained below (Eqs. 18, 23 and 24 respectively).

Infection and spore dispersal. Our model keeps track of the number of spores released during each dispersal event, whether they stay in their native field or not. We thus compute the number of spores present in each field and potentially able to infect the crop at every time step. In our model, we distinguish between spores of four different origins: (i) the external primary inoculum, i.e. spores entering the landscape from the outside, corresponding to long-distance dispersal events $P_{\text {external }}(k)$; (ii) spores produced within the field during the current year's epidemic $P_{\text {released }}(k)$; (iii) incoming spores produced by infectious neighbours in the landscape $P_{\text {neighbours }}(k)$; and (iv) spores accumulated in the field's spore pool over time that still participate in the current's year epidemic $P_{- \text {pool }}(k)$.

(i) The arrival of external spores occurs every year in our simulations, but is limited in both space and time. Only a fraction $p$ of the $N$ fields gets infected by the external inoculum, and the arrival of that inoculum is limited to a temporal window of $k_{C l}=200 \mathrm{dd}$ long, starting at $k=k_{\text {start }}$. The value of $k_{\text {start }}$ depends on the nature of the disease (Table 1). Fields get inoculated at a constant rate $P_{\text {ext, }, 0}$. This leads to the following number of spores in each of the $N p$ inoculated fields:

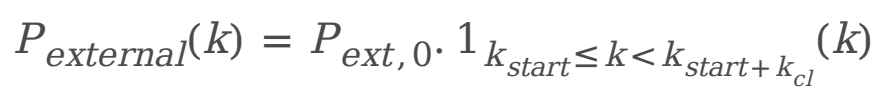

The $N p$ fields receiving external inoculum are randomly chosen every year. The first season's epidemic in each simulation is initiated by the arrival of the external inoculum. After that, during the following cropping seasons, infection starts at $k=k_{\text {start }}$ mainly through infection by spores inherited from the previous year's epidemic (see below), although arrival of external inoculum continues to occur at that date. 
(ii) Once an epidemic has started, the number of spores produced and dispersed within an infected field at every time step $k$ is given by:

$$
P_{\text {released }}(k)=(1-\alpha) \sigma I_{k^{*}} d(k)
$$

(Eq. 10)

where $\sigma$ is the pathogen spore production rate. The interpretation of the parameter $\alpha$ depends on the pathogen species. In the case of WLR, $\alpha$ corresponds to the fraction of spores (urediospores) leaving the field. Thus, $(1-\alpha)$ corresponds to the fraction of spores remaining in their natal field. In the case of STB, $\alpha$ corresponds to the fraction of spores dispersed by wind (ascospores), not rain (pycnidiospores). Consequently, the $(1-\alpha)$ rain-splashed pycnidiospores are also unable to leave their native field. The dispersal function $d(k)$ thus differs between the two pathogens. Since WLR urediospores are airborne and are released daily, we implemented a regular dispersal every 20 degree-days. Since STB pycnidiospores are rain-splashed, we used several weather time series recorded at Grignon experimental station between 1994 and 2006 to generate several annual rain patterns (the rain function in Eqs. 11 and $15)$ corresponding to more or less favourable weather conditions for pathogen development. An example of rain pattern is given in Supplementary Fig. 1 (lower panel). The dispersal function $d(k)$ is given by:

$$
d(k)=\left\{\begin{array}{c}
\text { wind }(k)=\left\{\begin{array}{c}
1 \text { if } k \equiv 0(20) \\
0 \text { otherwise }
\end{array}\right. \text { for WLR } \\
\text { rain }(k) \text { for STB }
\end{array}\right.
$$

(Eq. 11)

(iii) Infectious fields are a source of inoculum for their neighbours. The quantity of spores received by a given field depends on the number, distance, and spore production rate of its infectious neighbours. Let $A$ be a receptor field and $\mathrm{B}$ one of its infectious neighbours. Let $\delta_{A B} \leq \Delta$ be the distance between $\mathrm{A}$ and $\mathrm{B}$, where $\Delta$ is the maximum dispersal distance of the pathogen. The number of spores transmitted from $B$ to A decreases with increasing $\delta_{A B}$. But here again, we must distinguish between STB and WLR. In the case of WLR, all (uredio)spores produced could theoretically be blown away by wind and leave their natal field. We denote by $\alpha$ the fraction of spores produced in a given field that leaves it and contributes to the landscape-scale spread of the disease. To simulate that, we define $\Gamma_{W L R, A}$ as the set of fields which centre is within the Euclidian distance $\Delta$ of $A, A$ not included. The number of spores received by $A$ is the sum of the spores emitted by its neighbours towards it. In the case of STB, we distinguish between rainsplashed spores (a fraction $(1-\alpha)$ of the spores produced) and wind-dispersed spores (the remaining $\alpha$ ). Only the latter can potentially leave their natal field and contribute to landscape-scale disease spread. But many of them will undoubtedly land within their natal field before some of them are able to disperse further (Frezal et al. 2009). To simulate that, we define $\Gamma_{S T B, A}$ as the set of fields which centre is within the Euclidian distance $\Delta$ of $\mathrm{A}, \mathrm{A}$ included (in that case, $\delta_{A A}=0$ ). It follows that: 


$$
P_{\text {neighbours }}^{A}(k)=\left(\sum_{B \in \Gamma_{*, A}} \frac{1}{W_{A}} \cdot \frac{1}{\delta_{A B}+1} \alpha \sigma I_{k}^{B}\right) \cdot d(k)
$$

(Eq. 12)

with

$$
W_{A}=\sum_{B \in \Gamma_{*, A}} \frac{1}{\delta_{A B}+1}
$$

(Eq. 13)

where * denotes the type of pathogen (STB or WLR).

(iv) Finally, all spores received from the outside of the field or released within the field join a general pool of spores $P$ corresponding to the spores that did not succeed in infecting plants and have fallen to the ground or on non-susceptible plant surfaces. The pool of spores plays an important role at the beginning of epidemics, since a fraction $\theta$ of these spores survives the interculture period between two successive growing seasons and joins the external inoculum to create the first lesions at $k_{\text {start }}$ We model this survival of spores during the interculture as an instantaneous projection of the number of spores in the pool at harvest $\left(k=k_{\text {end }}\right)$ to the start of the next growing season $\left(k=k_{\text {init }}\right)$. With $T$ and $T+1$ being two consecutive growing seasons, we get:

$$
P_{k_{\text {init }}}^{T+1}=\theta P_{k_{\text {end }}}^{T}
$$

(Eq. 14)

Depending again on the pathogen species, spores from that pool can also be remobilized and participate to the creation of new lesions. Spores from STB survive well on the ground and on crop residues and can be rain-splashed from the ground onto seedlings for $k_{\text {start }} \leq k<k_{\text {pool }}$. Spores from WLR have a lower survival rate (because the biotrophic pathogen needs volunteer plants to survive the interculture) but can be remobilized throughout the course of the epidemic.

$$
P_{- \text {pool }}(k)=\left\{\begin{array}{c}
P_{k}\left(1-\frac{k-k_{\text {start }}}{k_{\text {pool }}-k_{\text {start }}}\right) \cdot \operatorname{rain}(k) \cdot 1_{k_{\text {start }} \leq k \leq k_{\text {pool }}} \text { for STB } \\
P_{k} \cdot \operatorname{wind}(k) \cdot 1_{k \geq k_{\text {start }}} \text { for WLR }
\end{array}\right.
$$

(Eq. 15)

Therefore, at any time $k$ during the year, the number of spores present in a field can be calculated as: 


$$
N_{\text {sp }}(k)=P_{\text {external }}(k)+P_{- \text {pool }}(k)+P_{\text {released }}(k)+P_{\text {neighbours }}(k)
$$

(Eq. 16)

In a given field, the inoculum $N_{s p}(k)$ spreads within the canopy where it is intercepted at a rate $\epsilon(k)$ by crop leaves. Spore interception by the crop canopy follows a Beer-Lambert equation:

$$
\epsilon(k)=1-e^{-b L A I \cdot(k)}
$$

(Eq. 17)

where $b$ is equivalent to the molar extinction coefficient of the Beer-Lambert law. Note that spores intercepted by the resistant plants, either in crop mixtures or in a resistant field in mosaics and rotations, do not contribute to the epidemics and are removed from the system. The spores that are not intercepted by any part of the canopy fall to the ground and build the pool of spores $P$. The number of spores intercepted by the canopy at time $k$ is thus $\epsilon(k) N_{s p}(k)$. To simulate crop infection, we subdivided the susceptible part $S$ of the canopy into elementary surfaces of size $s_{0}$. Each elementary surface can be infected only once. Intercepted spores will create lesions in the susceptible canopy with a probability $\Pi_{\text {inf }}$ Hence, the number of lesions produced in the canopy at a given time follows a Poisson distribution. The proportion of the canopy that intercepts infecting spores and thus becomes infected is given by Eq. 18 .

$$
c(k)=1-\exp \left(\frac{\Pi_{i n f} \epsilon(k) N_{s p}(k)}{\frac{S_{k}}{s_{0}}}\right)
$$

(Eq. 18)

Spores that were not intercepted by the canopy and spores that were intercepted by the canopy but did not cause lesions join the pool of spores $P$. Spores in $P$ decay at a constant rate $\rho$ and contribute, at each time step, to the within-field infection of susceptible tissue via the function $P_{- \text {pool }}(k)$ (Eq. 15). The dynamics of $P$ are thus given by:

$$
P_{k+1}=P_{k}(1-\rho)-P_{-p o o l}(k)+(1-\epsilon(k)) N_{s p}(k)+\left(1-\Pi_{i n f}\right) \epsilon(k) N_{s p}(k)
$$

(Eq. 19)

Age-structured latent period. Symptoms of the disease do not appear immediately after leaf infection. They appear after an incubation period. Spore production begins after an even longer period called the latent period ( $\lambda$ in our model). To ensure that the elementary surfaces $s_{0}$ remain exposed during the 
latent period, we must keep a record of the surface of the exposed tissue over time. In our model, we describe latent infected surfaces using an age-structured vector $\eta_{k}$ :

$$
\eta(k)=\left(\eta_{k, 1} \eta_{k, 2} \vdots \eta_{k, \lambda}\right)
$$

(Eq. 20)

where $\eta_{k, t}$ is the fraction of $E_{k}$ that got infected $t$ time steps ago. Thus, $\eta_{k, 1}$ corresponds to the fraction of $E_{k}$ that just got infected and $\eta_{k, \lambda}$ is the fraction of $E_{k}$ that will become infectious. Thus, at any time step $k$, the exposed surface can be calculated as:

$$
E_{k}=\sum_{i=1}^{\lambda} \eta_{k, i}
$$

(Eq. 21)

The vector $\eta$ thus corresponds to the age structure of the exposed crop surfaces. The components of the vector $\eta$ change according to the following rules:

$\backslash$ left $\backslash\left\{\text { begin }\{\text { array }\}\{c\}\{\backslash \text { eta }\}_{-}\{k+\backslash \text { text }\{1,1\}\}=\{c \backslash \text { left(k } \backslash \text { right }) S\right\}_{-}\{k\} \backslash \backslash\{\backslash \text { eta }\}_{-}\{k+1, i\}=\backslash$ eft $(1-\backslash$ mu $\backslash$ right $)\{\backslash$ eta

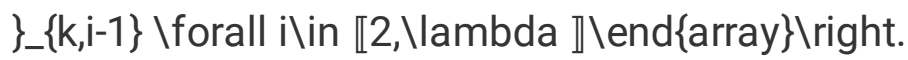

(Eq. 22)

where $c \backslash$ left(k\right) is the infection rate from Eq. 18.

Thus, the transition rate between infected tissue $E$ and infectious tissue / is given by:

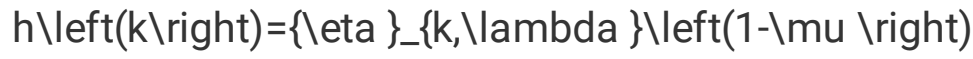

(Eq. 23)

Emptying of reproductive structures. As time goes on and spore dispersal occurs, older sporulating structures get progressively empty at a rate $\backslash p s i \backslash$ left(k $\backslash$ right). This rate depends on the frequency of dispersal events and on the average efficiency of individual dispersal events, which is, in turn, linked to the number of spores per reproductive structure.

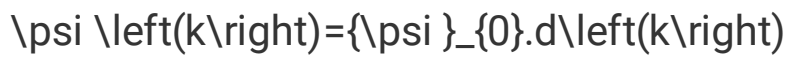

(Eq. 24)

with $d(k)$ the dispersal function described by Eq. 11. But owing to the difference in the number of spores between pycnidia of STB and uredia of WLR, we decided that the number of spores per uredium was not likely to be limiting ( $\{\backslash p s i\}\{\{0\}=0$ for WLR).

\section{Simulating crop diversification}


We use the model to simulate three strategies of crop diversification: within-field crop mixtures, crop rotations and landscape-scale crop mosaics (Fig. 1).

Crop mosaics. Crop mosaics correspond to landscape grids where fields planted only with the susceptible crop (hereafter called "susceptible fields") and others planted only with the resistant crop (hereafter called "resistant fields") coexist. Resistant fields display a S-R structure identical to that of a healthy canopy since we only consider complete (qualitative) resistance. The dynamics of resistant fields are thus given by Eq. 1-3. The dynamics of susceptible fields are given by Eq. 4-24. In a mosaic landscape, resistant and susceptible fields are randomly distributed across the landscape (Fig. 1). The spatial structure of mosaics remains the same throughout the 10 years of the simulations.

Crop rotations. We modelled crop rotations by implementing two types of rotations (Fig. 1). In synchronous rotations, all the fields in the landscape are either susceptible or resistant. In asynchronous rotations, susceptible and resistant fields coexist in the landscape in constant proportions every year. In asynchronous rotations, susceptible and resistant fields are randomly selected at the beginning of each simulation. Since a given field is alternatively planted with susceptible wheat and resistant crops during one simulation, crop rotations therefore correspond to crop mosaics changing through time.

Crop mixtures. Crop mixtures correspond to landscapes where all fields are similar. Diversification takes place at the field scale. Within a field, the canopy of the crop is divided into two parts: qualitatively resistant and susceptible. We will denote by $S^{r}$ and $R^{r}$ the healthy and removed parts, respectively, of the canopy corresponding to resistant crops. The total leaf area index (LAl) of a field is then divided into six parts: $S, E, I, R, S^{r}$ and $R^{r}$, so that:

$\{L A \mid\}_{-}\{k\}=\{S\}_{-}\{k\}\{+E\}_{-}\{k\}+\{\mid\}_{-}\{k\}+\{R\}_{-}\{k\}+\{S\}_{-}\{k\}^{\wedge}\{r\}+\{R\}_{-}\{k\}^{\wedge}\{r\}$

(Eq. 25)

Mixtures have the same global carrying capacity $K$ as susceptible and resistant fields but the carrying capacity is divided between the susceptible and the resistant parts of the canopy according to the percentage of susceptible and resistant hosts in the mixture \omega. Thus, for a fraction \omega of susceptible crop in the mixture, one can derive the dynamics of the system by substituting $K$ for $\{K\}^{\wedge}\left\{\mid t_{\text {text }}\{\}\right\}=K$ lomega in Eqs. 1, 2 and 4. Note however that there is no difference between $\{S\}_{-}\{k\}$ and $\{S\}_{-}\{k\}^{\wedge}\{r\}$ in terms of spore interception: both parts of the canopy contribute to spore interception even though the pathogen can only infect and reproduce on susceptible plants.

Effects of crop diversification strategies on fungal diseases. Since the spores intercepted by the resistant plants (either in crop mixtures or in resistant fields in mosaics and rotations) do not contribute to the epidemics and are removed from the system, a major regulating mechanism involved in all three crop diversification strategies is a dilution effect. Indeed, the resistant crop reduces the density of susceptible crop and intercepts pathogen spores, thus limiting pathogen spread between susceptible plants 
(processes reviewed by Mundt 2002). In our model, the dilution effect might be stronger in mixtures than in mosaics and rotations since a large fraction (1-lalpha) of the spores do not leave their native field.

Another regulating mechanism involved in rotations is inoculum mortality in the absence of the host (Hossard et al. 2018). We modelled the inoculum-suppression effect of rotations through a constant decay rate of the spore pool in every field of the landscape ( $\rho$ parameter, Eq. 19). In susceptible fields, new epidemics increase the pool of spores and compensate for the spore pool decay rate so that inoculum accumulates. In resistant fields, no epidemic occurs and the spore pool only decays until the field becomes susceptible and infected again. Moreover, every year, only a fraction $\theta$ of spore pool survives the interculture (Eq. 14).

Percentage of susceptible and resistant crop in the landscape. For each of the three crop diversification strategies, we simulate landscapes with different proportions of susceptible wheat. For mixtures, we compare epidemics when decreasing the proportion of susceptible wheat in the field from \omega $=100 \%$ (entirely susceptible) to \omega $=0 \%$ (entirely resistant). Note that for mixtures, we assume that each field in the landscape has the same fraction of susceptible wheat (Fig. 1). Consequently, for mixtures, the proportion of wheat in each individual field in the landscape is the same as the proportion of wheat in the landscape. The percentage of wheat in mixtures thus also corresponds to the fraction of susceptible plants in the whole landscape. For crop mosaics, we compare epidemics when decreasing the proportion of susceptible wheat fields from \omega $=100 \%$ (susceptible fields only) to \omega $=0 \%$ (resistant fields only) in the landscape. For both synchronous and asynchronous rotations, we vary the proportion of wheat in the landscape by simulating two-year cyclical models (resistant-susceptible, r-s) and three-year cyclical models (s-s-r and s-r-r). This corresponds to average proportions of resistant crops in the landscape (over a full rotation cycle) of \omega $=50 \%$, \omega $=33 \%$, and $\backslash$ omega $=67 \%$ respectively.

\section{Simulation equilibrium and output variable}

During each simulated cropping season, we follow the pathogen development in each field of the landscape. After 10-12 seasons, the system reaches a one-season epidemiological equilibrium cycle in the case of crop mixtures and mosaics, and a two-season or three-season equilibrium cycle in the case of two-year and three-year crop rotations, respectively. To estimate the epidemic levels at equilibrium in landscapes with crop mixtures, mosaics and rotations, we compute the area under disease progress curve (AUDPC, Madden et al. 2007) over the duration of the equilibrium cycle. Commonly used in plant epidemiology, AUDPC corresponds to the total area of crop covered by the disease in a given field during one cropping season. It is a quantitative summary of disease intensity over time that allows between-year and between-field comparisons. In our simulated landscapes, it is calculated as the average value over the $N$ wheat-containing fields of the landscape of the total diseased area / of each field:

AUDPC $=\backslash$ frac $\{1\}\{N\}\{\mid \text { sum }\}_{-}\{i=1\}^{\wedge}\{N\}\{\backslash \text { sum }\}_{-}\{j=0\}^{\wedge}\left\{\{k\}_{-}\{e\}\right\}\{\mid\}_{-}\{i, j\}$

(Eq. 26) 
For crop mixtures, AUDPC values correspond to the landscape-scale average epidemic levels of the wheat plants in the mixtures at equilibrium. For crop mosaics, AUDPC values correspond to the landscape-scale average epidemic levels of the wheat fields at equilibrium. For crop rotations, AUDPC corresponds to the landscape-scale average epidemic levels in wheat fields averaged over the duration of the rotation cycle.

\section{Simulation schedule}

For the three diversification strategies, we simulate epidemics in the fields of the landscape under three sets of meteorological conditions that are more or less favourable to STB and WLR (Fig. 2). We used temporal patterns of rainfall recorded at the experimental site of Grignon (Fr-78850) between 1993 and 2006 to select favourable and unfavourable rain patterns for STB simulations. For this, following Robert et al. (2008) and Garin et al. (2014), we analysed rainfall patterns that take the form of "rain combs" in which each "tooth" represents a pathogen dispersal event (Supplementary Fig. 1). We chose three of these rain patterns to represent favourable, average and unfavourable annual weather for STB epidemics: 1994-95 was a favourable year for STB: very rainy winter and regular rain events during plant growth in spring. Conversely, 1996-97 was unfavourable: there was little rainfall throughout the year. We also use the more realistic sequence corresponding to the years 1994 to 2006, which includes both favourable, average and unfavourable years as an average condition (Supplementary Fig. 1). For WLR, following Duvivier et al. (2016) and Garin et al. (2018), we use the date of the onset of the epidemics to simulate favourable and unfavourable weather scenarios. Favourable weather leads to epidemics starting $800 \mathrm{dd}$ after sowing while unfavourable weather leads to epidemics starting $1200 \mathrm{dd}$ after sowing. Average weather conditions lead to epidemics starting $1000 \mathrm{dd}$ after sowing (Supplementary Fig. 2).

To extend the robustness of our results, we explore the impact of crop diversification by varying different parameters of the infection cycles of the pathogens: inoculum survival (\theta, Fig. 3) and the intraseason spore mortality rate (\rho, Supplementary Fig. 3). These pathogen traits are important for disease development. Moreover, these traits could respond to weather conditions. For instance, spore overwintering could become easier for pathogens as winters become milder. Summer droughts could make survival during the interculture more difficult if it reduced the availability of volunteer plants or increased spore decay caused by UV radiation and high temperatures. Favourable climatic conditions on a broader scale may lead to a global increase in pathogen populations, thereby increasing the inoculum pressure at a regional scale and the pressure of an external inoculum the beginning of epidemics.

\section{Model parameters and implementation}

The model was parameterized according to our knowledge of the two pathosystems in order to allow for qualitatively consistent results with epidemiological data from the literature or data collected at the Grignon experimental site (Robert et al. 2004, 2005; Frezal et al. 2009; Pariaud et al. 2009; Baccar et al. 2011) and already used in previous modelling studies (Robert et al. 2008, 2018; Garin et al. 2014). Hence, parameters of the model were chosen so that maximum disease severity did not exceed two-thirds of the LAI for STB and one-half of the LAI for WLR (Bancal et al. 2007). This difference explains why maximum disease severity in our simulations is higher for STB than for WLR. Differences in parameter values are 
inspired by findings of Robert et al. $(2008,2018)$, Garin et al. $(2014,2018)$, and Précigout et al. $(2020$ b). Examples of disease dynamics and sensitivity to weather conditions can be found in Supplementary Figs. 1 and 2. The model was developed with MatLab (2020). 
Table 1

model parameters, values and interpretation. dd: degree-days, [LAl]: leaf area index unit $\left(\mathrm{m}^{2}\right.$ of leaf per $\mathrm{m}^{2}$ of ground).

\begin{tabular}{llll} 
Symbol & \multicolumn{1}{l}{ Value } & Unit Interpretation \\
\cline { 2 - 3 } & WLR & STB &
\end{tabular}

\section{Landscape parameters}

\begin{tabular}{llll}
$N$ & 1089 & fields & Number of fields in the landscape \\
$p$ & 0.01 & - & $\begin{array}{l}\text { Fraction of fields infected at the beginning of } \\
\text { each simulation }\end{array}$ \\
$\begin{array}{l}\{\text { Idelta } \\
\}_{\{}\{A B\}\end{array}$ & - & fields & Euclidian distance between two fields $A$ and $B$ \\
\hline
\end{tabular}

\section{Seasonal dynamics}

\begin{tabular}{|c|c|c|c|c|}
\hline$k$ & $\multicolumn{2}{|c|}{k}_{-}\{$init $\}\{k\}_{-}\{$end $\}$ & dd & Time index within a year \\
\hline$T$ & $1-12$ & & - & Year (crop growing season) index \\
\hline$\{k\}_{-}\{$init $\}$ & 0 & & dd & Start of season \\
\hline$\{k\}_{-}\{$start $\}$ & $800-1300$ & 0 & dd & $\begin{array}{l}\text { Arrival date of primary inoculum (annual start } \\
\text { date of epidemic) }\end{array}$ \\
\hline$\{k\} \_\{g r o w t h\}$ & 1400 & & dd & End of period of canopy growth \\
\hline$k_{c l}$ & 200 & & dd & $\begin{array}{l}\text { Time period during which the crop is exposed to } \\
\text { external primary inoculum }\end{array}$ \\
\hline$\{\mathrm{k}\} \_\{\text {pool }\}$ & Ivarnothing & 700 & dd & $\begin{array}{l}\text { Time period during which the crop is exposed to } \\
\text { primary inoculum by spores from the spore pool }\end{array}$ \\
\hline$\{\mathrm{k}\}_{-}\{$end $\}$ & 2500 & & dd & End of season \\
\hline
\end{tabular}

\section{Crop dynamics}

\begin{tabular}{|c|c|c|c|}
\hline K & 6 & [LAl] & Maximum value of Leaf Area Index (LAl) \\
\hline Ibeta & 0.09 & $\begin{array}{l}{[\text { LAll]/(10 }} \\
\text { dd) }\end{array}$ & Growth rate of the green Leaf Area Index (gLAl) \\
\hline Imu & 0.03 & $\begin{array}{l}{[\mathrm{LAl}] /(10} \\
\mathrm{dd})\end{array}$ & Mortality rate of plant tissue \\
\hline lomega & $0.1-1$ & - & $\begin{array}{l}\text { Fraction of susceptible crop in } \\
\text { mixtures/landscapes }\end{array}$ \\
\hline \multicolumn{4}{|c|}{ Pathogen dynamics \& dispersal } \\
\hline$\{P\}_{-}\{e x t, 0\}$ & 20000 & spores & External primary inoculum \\
\hline$\lambda$ & 100 & dd & Latent period \\
\hline
\end{tabular}




\begin{tabular}{|c|c|c|c|c|}
\hline \multirow[t]{2}{*}{ Symbol } & \multicolumn{2}{|l|}{ Value } & \multirow[t]{2}{*}{ Unit } & \multirow[t]{2}{*}{ Interpretation } \\
\hline & WLR & STB & & \\
\hline $\mathrm{b}$ & 1 & & {$[\mathrm{LAl}]^{-1}$} & Spore interception rate by the canopy \\
\hline$\{s\}_{-}\{0\}$ & 1 & & $\mathrm{~cm}^{2}$ & Individual lesion size \\
\hline$\{\backslash p i\}_{-}\{$inf $\}$ & 0.0002 & & - & Infection probability \\
\hline \sigma & $1.5 \times 10^{6}$ & $5.0 \times 10^{7}$ & {$[\mathrm{LAl}]^{-1}$} & Spore production rate \\
\hline Itheta & 0.01 & 0.15 & - & Spores survival rate during the intercropping \\
\hline \rho & 0.01 & 0.002 & - & Spore mortality rate \\
\hline \alpha & 0.5 & 0.02 & - & $\begin{array}{l}\text { Fraction of spores leaving their natal field } \\
\text { (WLR); fraction of sexual airborne spores } \\
\text { produced (STB) }\end{array}$ \\
\hline$\{\backslash p s i\}_{-}\{0\}$ & 0.3 & 0 & - & $\begin{array}{l}\text { Emptying rate of pathogen reproductive } \\
\text { structures }\end{array}$ \\
\hline IvarDelta & 5 & 2 & fields & Maximum dispersal distance of the pathogen \\
\hline
\end{tabular}

\section{Results}

For both pathogen species and the three diversification strategies, epidemic intensity (AUDPC) decreased with the decreasing proportion of susceptible wheat within fields and in the landscape (Fig. 2). As expected, we found that for both pathogens, unfavourable weather conditions lead to low epidemic levels regardless of the diversification strategy and regardless of the proportion of wheat in mixtures, rotations and mosaics. Epidemic intensity for WLR peaked when the epidemics started early (800 degree-days (dd), i.e. favourable weather conditions, Fig. 2A) and stayed very low when the epidemics started late (1200 dd, adverse weather conditions, Fig. 2C). The maximum AUDPC of STB was 125 times higher in very rainy years (favourable weather conditions, Fig. 2D) compared to AUPDC values in dry years (adverse weather conditions, Fig. 2F).

\section{Joint effects of crop diversification strategies and weather conditions}

Planting crop mixtures within fields was the diversification strategy that kept epidemic intensity at its lowest values compared to rotations and landscape mosaics. This result was consistent across all weather conditions and pathogens. We found a non-linear relationship between AUDPC in landscapes composed of crop mixtures and the proportion of wheat in the mixtures. Decreasing the within-field proportion of wheat from $100 \%$ (wheat monoculture) to $60 \%$ reduced AUDPC by $85 \%$ for WLR (Fig. 2B) and $98 \%$ for STB (Fig. 2E) under average weather conditions. But for both pathogens, reducing the 
proportion of wheat in fields below $50 \%$ did not decrease the level of disease regulation much further (AUDPC < 10). We can therefore identify a threshold in the proportion of wheat in mixtures below which increase in the proportion of resistant plants does not lead to further disease limitation. Remarkably, that threshold depended on weather conditions. While under favourable weather conditions for WLR, high disease limitation occurred when wheat did not exceed $30 \%$ of the mixture (Fig. $2 \mathrm{~A}$ ), wheat could represent up to $50 \%$ of the mixture under average weather conditions (Fig. 2B). Similarly, under favourable weather for STB, high disease limitation occurred when wheat did not exceed $50 \%$ of the mixture (Fig. 2D) but under average weather conditions, wheat could represent up to $60 \%$ of the mixture (Fig. 2E).

Synchronous and asynchronous crop rotations were the second most efficient strategy to limit STB epidemics under all weather conditions. Rotations were nearly as efficient as mixtures when wheat did not exceed $50 \%$ at the landscape scale (Fig. 2D-F). In contrast, the efficacy of crop rotations to limit WLR changed with weather conditions. When weather conditions were favourable to WLR, synchronous rotations were almost as good as mixtures (Fig. 2A). But, under average weather for WLR, rotations were less efficient than mixtures (except for synchronous rotations in landscapes with $33 \%$ of wheat, Fig. 2B).

Landscape crop mosaic was the least effective diversification strategy to reduce disease intensity compared to within-field mixtures and crop rotations, under both favourable and average weather conditions for both pathogens. Although less effective, landscape mosaics still impacted WLR epidemics. For example, under favourable weather conditions, halving the fraction of wheat fields in the landscape led to a linear reduction of $50 \%$ in WLR disease intensity (Fig. 2A). This effect was even stronger under average weather conditions: landscapes with $50 \%$ of fields with wheat displayed a disease reduction of $75 \%$ compared to monoculture wheat landscapes (Fig. 2B). For STB, mosaics of wheat and resistant crop exerted some biological control only when wheat fields represented less than $30 \%$ of the landscape (Fig. 2D and E). Overall, in our simulations the regulating impact of landscape mosaics and field crop rotations depended more on both the identity of pathogen and the weather conditions compared to within-field crop mixtures.

\section{Pathogen survival and inoculum pressure}

Higher inoculum survival during interculture (Fig. 3) and lower spore mortality during the cropping season (Supplementary Fig. 3) both increased the intensity of epidemics of both pathogens. For the three diversification strategies, the higher the inoculum survival, the higher the proportion of resistant crop required within or between fields to limit the diseases. For instance, $20 \%, 40 \%$ and $60 \%$ of resistant plants were needed to limit STB in within-field mixtures under low, medium and high inoculum survival (Fig. 3DF), respectively. We found comparable results for decreasing levels of intra-season spore mortality (Supplementary Fig. 3D-F).

Although their effectiveness depended on inoculum survival and spore mortality, crop mixtures remained the most effective strategy to limit epidemics in nearly all simulations. There was however one notable 
exception for WLR: synchronous rotations with an average of $67 \%$ wheat in the landscape (two years of wheat out of three successive years) succeeded in keeping epidemic intensity low despite high inoculum survival rates (Fig. $3 \mathrm{C}$ ). In this specific situation, synchronous rotations limited rust epidemics better than mixtures.

\section{Discussion}

Using a mathematical model to simulate epidemics at multiple spatial and temporal scales, we found that within-field crop mixtures, crop rotations and crop mosaics at the landscape scale all succeed in limiting epidemics of STB and WLR. Our results are consistent with experimental and modelling studies that focused on each of these strategies individually (Mundt 2002; Papaïx et al. 2014b; Hossard et al. 2018). Importantly, we found that within-field crop mixtures consistently outperform rotations and landscape crop mosaics in limiting epidemics regardless of pathogen identity and weather conditions. Although previous modelling attempts to compare pairs of these strategies found a stronger impact of, respectively, crop mixtures (Skelsey et al. 2010) or crop rotations (Fabre et al. 2015) over landscape crop mosaics, to our knowledge this is the first study (in silico) that compares and ranks the potential of more than two diversification strategies to limit epidemics. Our study also brings new insights into the regulating service provided by crop rotations, a quantitate assessment mainly missing for pathogenic fungi. The joint theoretical study of these pesticide-free diversification practices on different crop pathogen species and under different weather conditions opens avenues worth exploring to ensure sustainable disease control provided by crop diversity.

Our simulations show that even a relatively small increase in crop diversity compared to wheat monocultures may lead to greatly decreased intensity of epidemics, especially in crop mixtures (Figs. 2B, $2 \mathrm{E}, 3 \mathrm{~B}, 3 \mathrm{E})$. Indeed, in most simulations, we found that decreasing the proportion of wheat in mixtures from $100 \%$ (monoculture) to a certain threshold (between $60 \%$ and $40 \%$ ) reduces disease intensity tenfold, with no additional significant benefits coming from further reduction of wheat. Other studies assessing the regulating effect of cultivar mixtures on STB (Ben M'Barek et al. 2020), or of natural and semi-natural habitats on fungal pathogens (Knops et al. 1999) and aphids (Le Gal et al. 2020), reached similar conclusions. Quantification of such threshold through experimental inoculation of fields including various levels of wheat could provide the practical information needed (Borg et al. 2018) to design crop mixtures efficient under specific weather conditions. Interestingly, our results further show that the value of this threshold depends on weather conditions (Figs. 2A 2D, 3C, 3F). The more favourable the weather for the pathogen, the higher this threshold (i.e. less wheat and more resistant crop are needed). This suggests that diversification strategies will be more effective in epidemics of limited intensity and that higher levels of diversification may be needed to limit epidemics in areas where climatic conditions are more favourable for the pathogens or more variable.

Our model reveals, in line with previous studies (Burdon et al. 2014), strong interactions between pathogen traits, the scale of crop diversification and weather conditions on disease limitation. For example, in landscape mosaics under average weather conditions, low proportions of wheat fields in the 
landscape are enough to strongly reduce WLR epidemics (pathogen with high dispersal levels at the landscape scale, Fig. 2B, 3B), while high proportions of wheat are required to achieve STB limitation (pathogen with limited dispersal for which the intensity of the disease is mostly determined by within-field conditions Fig. 2D-E, 3E-F). We find no such difference for within-field mixtures, which exert comparable levels of regulation on both pathogens.

Furthermore, we find that crop rotations (and in particular synchronous rotations) go from the least effective strategy to limit WLR in unfavourable weather conditions to very effective in favourable conditions (Figs. 2A and 2C). This is not the case for STB epidemics, for which crop rotations have a consistently strong impact under all weather conditions (Figs. 2D and 2E). This difference between the two pathogens is consistent with previous experimental results (Bullock 1992), showing that crop rotations are generally more effective against soil-borne pathogens with a limited range of dispersal than against broadly dispersed airborne pathogens.

Our results therefore confirm the importance of accounting for interactions between pathogen traits, weather conditions and the scale of crop diversification strategies to explain the disease-limitation properties of the latter. An interesting perspective to this work would be to test the combined effects of such strategies at the field and landscape scales. Benefits of increasing the proportion of mixtures in the landscape in addition to a diversified array of crops could increase the potential for higher levels of pathogen limitation, in a given climate or under different climatic conditions (Skelsey et al. 2010; Papaïx et al. 2014a, b).

Climate is one of the most important factors in the development of epidemics and scientists agree that climate change will impact epidemics, either positively or negatively (Luck et al. 2011). In Europe, where wheat represents almost $50 \%$ of the production of cereals, climate projections predict a general increase in annual temperatures with increased winter precipitation and warmer and drier conditions in spring and summer (Kovats et al. 2015). Wheat production has already suffered from these changes (Lobell et al. 2011) and the impact of climate change on pathogens could make things worse. In our model and in former studies, dryer spring conditions are unfavourable to STB spore dispersal, which is dependent on rain splashes. Thus, although predictions vary, notably with location (West et al. 2012; Gouache et al. 2013), STB incidence could be reduced with climatic change, especially in southern Europe (Boland et al. 2004; Cotuna et al. 2018). Regarding WLR, warmer springs are likely to favour the early establishment of the pathogen (Boland et al. 2004; Grabow et al. 2016), which could lead to stronger epidemics (West et al. 2012; Junk et al. 2016). Our model consistently reproduces this mechanism with an early start of the epidemic leading to an increase in WLR epidemic intensity (Fig. 3A). These results are also consistent with recent observations of more damageable rust epidemics in recent years in Europe (Bhattacharya 2017; Saunders et al. 2019), with reported yield losses up to 30-40\% (Saunders et al. 2019). Finally, increased winter temperatures could favour overwintering of both pathogens (Xu et al. 2019), leading to a decrease in disease limitation efficacy of all crop diversification strategies (Fig. 3). Therefore, climatic conditions that favour inoculum survival, such as milder winters, will likely threaten the durability of disease regulation systems based on crop diversification alone (Brown and Hovmøller 2002). 
Choosing among biodiversity-based strategies that limit the development of diseases under increasingly erratic seasonal weather will be challenging. Instead of opting for strategies conferring a strong protection against diseases but in specific environments, one could opt for a more limited protection, but effective in a wider range of climatic contexts. In our model, synchronous rotations provide this kind of insurance against WLR, and so do mixtures containing 50\% wheat or less against both diseases. Choice among these strategies will also be guided by practical and economic aspects. Crop diversification may pose numerous practical problems. For example, farm machinery and grain outlets have historically developed in the context of simplified intensive systems based on monocultures. Switching strategies to include crop mixtures and more diversified crop landscapes into agricultural systems thus faces multiple socio-economic and technical challenges (Newton 2009; Meynard et al. 2018). Despite these challenges, the use of crop mixtures and cultivars has increased in France in recent years and the disease reduction they provide could be a contributing factor in their success (Vidal et al. 2020). Beyond new ecological and agronomic knowledge, an optimal diversification of agricultural landscapes requires taking into account multiple dimensions of agricultural territories. This includes cooperation between farmers and stakeholders as well as a territorial organization undoubtedly beyond that of the farms and farmers alone. Combining epidemiological understanding and sociological and technical issues is necessary in the perspective of agricultural transition (Lescourret et al. 2015). Models such as the one we have developed here can prove interesting tools to exchange not only with researchers but also with farmers and agricultural stakeholders in order to simulate transition scenarios at different scales. The inclusion of more realistic, and innovative strategies from the agricultural world is an exciting prospect.

Finally, beyond disease control, crop diversification is known to contribute to different functions such as maintaining production with less fertilizers (Borg et al. 2018), promoting soil fertility (Juskiw et al. 2000) and favouring associated and spontaneous biodiversity (Beillouin et al. 2019). However, the compositions of crop assemblages that would foster different ecosystem services may not be the same. It is therefore important to consider the possible synergies or antagonisms at work in combinations of diversification strategies (Beillouin et al. 2021). In this regard, including new ecological functions in our model is an interesting perspective.

As with all modelling studies, ours is subject to some limitations. Here we address some important ones. The first concerns our crop growth model at the field scale. In our study, the resistant crop has the same growth dynamics as the susceptible wheat, which is quite a big simplification. Indeed, Beillouin et al. (2021) show that cultivar mixtures, crop associations and agroforestry all have an impact on pests regulation but their impact is different due to different types of ecological interactions. Accounting for the type of diversification at the field scale would therefore be a great perspective in our model. Biotic interactions between wheat and the associated crop, such as competition for light (Barillot et al. 2012) or soil nutrients (Juskiw et al. 2000), which could impact crop growth dynamics in many different depending on the respective proportions of the two crops, would thus be interesting to take into account. Between plant interaction processes and their consequences in terms of canopy growth and epidemic development within the canopy are well simulated by FSPM models, which seek to represent the spatiotemporal dynamics of plant development and plant-pathogen interaction in three 
dimensions(Robert et al. 2008, 2018). But, due to their high level of refinement and subsequent complexity, these models may not be suitable for modelling a mixture at a larger scale than a few square meters of crop, and would therefore not be compatible with an ecological landscape modelling approach such as ours.

In addition, we have considered neither pathogen adaptation to the resistant crop through resistance breakdown, nor putative pathogen adaptation to ecological regulation due to the dilution effect. Resistance breakdown is rather commonplace (McDonald and Linde 2002; Burdon et al. 2014) and is likely to cancel the benefits conferred by crop diversification. For the moment, and with only a few exceptions (Fabre et al. 2015; Rimbaud et al. 2018a), the evolution of resistance breakdown and the effects of crop diversification on epidemics have been studied separately. However, Précigout et al. (2017, 2020 b) have recently shown possible adaptation of the pathogen to "soft regulation practices" such as reduction of fertilization levels, i.e. agricultural strategies aiming at limiting pathogen populations to acceptable levels through indirect effects on the crops for instance. Studies on the adaptation of pathogens to agroecological practices are needed to assess their sustainability or to propose solutions to make them more resilient to pathogen adaptation.

\section{Declarations}

\section{ACKOWLEDGEMENTS}

This work was funded by the French National Research Agency under the Programme "Investissements d'Avenir" under the reference ANR 17 MPGA 0004 and by the National Research Institute for Agriculture, Food and the Environment (INRAE). We thank Doyle McKey and Olivier Dangles for helpful comments during the preparation of the manuscript and English proofreading.

\section{FUNDING}

This work was funded by the French National Research Agency under the Programme "Investissements d'Avenir" under the reference ANR 17 MPGA 0004 and by the National Research Institute for Agriculture, Food and the Environment (INRAE).

\section{COMPETING INTERESTS}

The authors have no relevant financial or non-financial interests to disclose.

\section{AUTHOR CONTRIBUTIONS}

Conceptualization: D.C. \& C.R. Model Development: D.C., J.S. \& C.R. Simulation schedule: D.C., J.S., P-A.P. \& C.R. Simulation Analysis: P-A.P., D.R., D.C. \& C.R. Writing, Review and Editing: P-A.P., D.R. \& C.R. 
Data sharing not applicable to this article as no datasets were generated or analyzed during the current study. The Matlab implementation of the model is available upon request by e-mail to the corresponding author: pierre-antoine.precigout@inrae.fr.

\section{References}

1. Baccar R, Fournier C, Dornbusch T, et al (2011) Modelling the effect of wheat canopy architecture as affected by sowing density on Septoria tritici epidemics using a coupled epidemicvirtual plant model. Ann Bot 108:1179-1194. https://doi.org/10.1093/aob/mcr126

2. Bancal MO, Robert C, Ney B (2007) Modelling wheat growth and yield losses from late epidemics of foliar diseases using loss of green leaf area per layer and pre-anthesis reserves. Ann Bot 100:777789. https://doi.org/10.1093/aob/mcm163

3. Bargués-Ribera M, Gokhale CS (2020) Eco-evolutionary agriculture: Host-pathogen dynamics in crop rotations. PLoS Comput Biol 16:e1007546. https://doi.org/10.1371/journal.pcbi.1007546

4. Barillot R, Combes D, Chevalier V, et al (2012) How does pea architecture influence light sharing in virtual wheat-pea mixtures? A simulation study based on pea genotypes with contrasting architectures. AoB Plants 2012:pls038-pls038. https://doi.org/10.1093/aobpla/pls038

5. Barot S, Allard V, Cantarel A, et al (2017) Designing mixtures of varieties for multifunctional agriculture with the help of ecology. A review. Agron Sustain Dev 37:. https://doi.org/10.1007/s13593-017-0418-x

6. Beillouin D, Ben-Ari T, Makowski D (2019) Evidence map of crop diversification strategies at the global scale. Environ Res Lett 14:123001. https://doi.org/10.1088/1748-9326/ab4449

7. Beillouin D, Ben-Ari T, Malézieux E, et al (2021) Positive but variable effects of crop diversification on biodiversity and ecosystem services. Glob Chang Biol. https://doi.org/10.1111/gcb.15747

8. Ben M'Barek S, Karisto P, Abdedayem W, et al (2020) Improved control of septoria tritici blotch in durum wheat using cultivar mixtures. Plant Pathol 1-11. https://doi.org/10.1111/ppa.13247

9. Benbi DK (1994) Prediction of leaf area indices and yields of wheat. J Agric Sci 122:13-20. https://doi.org/10.1017/S0021859600065734

10. Bhattacharya S (2017) Wheat rust back in Europe. Nature 542:145-146

11. Boland GJ, Melzer MS, Hopkin A, et al (2004) Climate change and plant diseases in Ontario. Can J Plant Pathol 26:335-350. https://doi.org/10.1080/07060660409507151

12. Borg J, Kiær LP, Lecarpentier C, et al (2018) Unfolding the potential of wheat cultivar mixtures: A meta-analysis perspective and identification of knowledge gaps. F Crop Res 221:298-313. https://doi.org/10.1016/j.fcr.2017.09.006

13. Brown JKM, Hovmøller MS (2002) Aerial dispersal of fungi on the global and continental scales and its consequences for plant disease. Science (80- ) 297:537-541.

https://doi.org/10.1126/science.1072678

Page 23/30 
14. Bullock DG (1992) Crop rotation. CRC Crit Rev Plant Sci 11:309-326. https://doi.org/10.1080/07352689209382349

15. Burdon JJ, Barrett LG, Rebetzke G, Thrall PH (2014) Guiding deployment of resistance in cereals using evolutionary principles. Evol Appl 7:609-624. https://doi.org/10.1111/eva.12175

16. Caubel J, Launay M, Lannou C, Brisson N (2012) Generic response functions to simulate climatebased processes in models for the development of airborne fungal crop pathogens. Ecol Modell 242:92-104. https://doi.org/10.1016/j.ecolmodel.2012.05.012

17. Cotuna O, Paraschivu M, Paraschivu M, Olaru L (2018) Influence of Crop Management on the Impact of Zymoseptoria Tritici in Winter Wheat in the Context of Climate Change: an Overview. Res J Agric Sci 50:69-76

18. Duvivier M, Dedeurwaerder G, Bataille C, et al (2016) Real-time PCR quantification and spatiotemporal distribution of airborne inoculum of Puccinia triticina in Belgium. Eur $\mathrm{J}$ Plant Pathol 145:405-420. https://doi.org/10.1007/s10658-015-0854-x

19. El Jarroudi M, Kouadio L, Delfosse P, Tychon B (2014) Brown rust disease control in winter wheat: I. Exploring an approach for disease progression based on night weather conditions. Environ Sci Pollut Res 21:4797-4808. https://doi.org/10.1007/s11356-013-2463-6

20. Eversmeyer MG, Kramer CL (1998) Models of early spring survival of wheat leaf rust in the central Great Plains. Plant Dis 82:987-991. https://doi.org/10.1094/PDIS.1998.82.9.987

21. Eyal Z (1987) The Septoria Diseases of Wheat

22. Fabre F, Rousseau E, Mailleret L, Moury B (2015) Epidemiological and evolutionary management of plant resistance: Optimizing the deployment of cultivar mixtures in time and space in agricultural landscapes. Evol Appl 8:919-932. https://doi.org/10.1111/eva.12304

23. Finckh MR, Gacek ES, Czembor HJ, Wolfe MS (1999) Host frequency and density effects on powdery mildew and yield in mixtures of barley cultivars. Plant Pathol 48:807-816

24. Finckh MR, Gacek ES, Goyeau H, et al (2000) Cereal variety and species mixtures in practice, with emphasis on disease resistance. Agronomie 20:813-837. https://doi.org/10.1051/agro:2000177

25. Forsman K, Poutala T (1997) Crop Management Effects on Pre- and Post-Anthesis Changes in Leaf Area Index and Leaf Area Duration and their Contribution to Grain Yield and Yield Components in Spring Cereals. J Agron Crop Sci 61:47-61

26. Frezal L, Robert C, Bancal M-O, Lannou C (2009) Local dispersal of Puccinia triticina and wheat canopy structure. Phytopathology 99:1216-24. https://doi.org/10.1094/PHYTO-99-10-1216

27. Garin G, Fournier C, Andrieu B, et al (2014) A modelling framework to simulate foliar fungal epidemics using functional-structural plant models. Ann Bot 114:795-812. https://doi.org/10.1093/aob/mcu101

28. Garin G, Pradal C, Fournier C, et al (2018) Modelling interaction dynamics between two foliar pathogens in wheat: A multi-scale approach. Ann Bot 121:927-940.

https://doi.org/10.1093/aob/mcx186 
29. Gilligan $C$ a (2008) Sustainable agriculture and plant diseases: an epidemiological perspective. Philos Trans R Soc B Biol Sci 363:741-759. https://doi.org/10.1098/rstb.2007.2181

30. Gouache D, Bensadoun A, Brun F, et al (2013) Modelling climate change impact on Septoria tritici blotch (STB) in France: Accounting for climate model and disease model uncertainty. Agric For Meteorol 170:242-252. https://doi.org/10.1016/j.agrformet.2012.04.019

31. Grabow BS, Shah DA, Dewolf ED (2016) Environmental conditions associated with stripe rust in kansas winter wheat. Plant Dis 100:2306-2312. https://doi.org/10.1094/PDIS-11-15-1321-RE

32. Hinzman LD, Bauer ME, Daughtry CST (1986) Effects of Nitrogen-Fertilization on Growth and Reflectance Characteristics of Winter-Wheat. Remote Sens Environ 19:47-61. https://doi.org/Doi 10.1016/0034-4257(86)90040-4

33. Hossard L, Souchere V, Jeuffroy MH (2018) Effectiveness of field isolation distance, tillage practice, cultivar type and crop rotations in controlling phoma stem canker on oilseed rape. Agric Ecosyst Environ 252:30-41. https://doi.org/10.1016/j.agee.2017.10.001

34. Huang J, Sedano F, Huang Y, et al (2016) Assimilating a synthetic Kalman filter leaf area index series into the WOFOST model to improve regional winter wheat yield estimation. Agric For Meteorol 216:188-202. https://doi.org/10.1016/j.agrformet.2015.10.013

35. Junk J, Kouadio L, Delfosse P, El Jarroudi M (2016) Effects of regional climate change on brown rust disease in winter wheat. Clim Change 135:439-451. https://doi.org/10.1007/s10584-015-1587-8

36. Juskiw PE, Helm JH, Salmon DF (2000) Competitive ability in mixtures of small grain cereals. Crop Sci 40:159-164. https://doi.org/10.2135/cropsci2000.401159x

37. Knops JMH, Tilman D, Haddad NM, et al (1999) Effects of plant species richness on invasion dynamics, disease outbreaks, insect abundances and diversity. Ecol Lett 2:286-293. https://doi.org/10.1046/j.1461-0248.1999.00083.x

38. Kolster P, Munk L, Stolen O (1989) Disease Severity and Grain Yield in Barley Multilines with Resistance to Powdery Mildew. Crop Sci 29:1459-1463. https://doi.org/10.2135/cropsci1989.0011183X002900060027x

39. Kovats RS, Valentini R, Bouwer LM, et al (2015) IPCC Report 2014 - Europe. In: Climate Change 2014: Impacts, Adaptation, and Vulnerability. Part B: Regional Aspects. Contribution of Working Group II to the Fifth Assessment Report of the Intergovernmental Panel on Climate Change. pp 1267-1326

40. Le Gal A, Robert C, Accatino F, et al (2020) Modelling the interactions between landscape structure and spatio-temporal dynamics of pest natural enemies: Implications for conservation biological control. Ecol Modell 420:108912. https://doi.org/10.1016/j.ecolmodel.2019.108912

41. Lescourret F, Magda D, Richard G, et al (2015) A social-ecological approach to managing multiple agro-ecosystem services. Curr Opin Environ Sustain 14:68-75. https://doi.org/10.1016/j.cosust.2015.04.001

42. Lobell DB, Schlenker W, Costa-Roberts J (2011) Climate Trends and Global Crop Production since 1980. Science (80- ) 333:616-620. https://doi.org/10.4159/harvard.9780674333987.c22 
43. Luck J, Spackman M, Freeman A, et al (2011) Climate change and diseases of food crops. Plant Pathol 60:113-121. https://doi.org/10.1111/j.1365-3059.2010.02414.x

44. Madden L V., Hughes G, van den Bosch F (2007) The Study of Plant Disease Epidemics. The American Phytopathological Society, St. Paul, MN.

45. McDonald B a., Linde C (2002) Pathogen Population Genetics, Evolutionary Potential, and Durable Resistance. Annu Rev Phytopathol 40:349-379.

https://doi.org/10.1146/annurev.phyto.40.120501.101443

46. Meynard JM, Charrier F, Fares M, et al (2018) Socio-technical lock-in hinders crop diversification in France. Agron Sustain Dev 38:. https://doi.org/10.1007/s13593-018-0535-1

47. Mommer L, Cotton TEA, Raaijmakers JM, et al (2018) Lost in diversity: the interactions between soilborne fungi, biodiversity and plant productivity. New Phytol 218:542-553. https://doi.org/10.1111/nph.15036

48. Morais D, Sache I, Suffert F, Laval V (2016) Is the onset of septoria tritici blotch epidemics related to the local pool of ascospores? Plant Pathol 65:250-260. https://doi.org/10.1111/ppa.12408

49. Mundt CC (2002) Use of Multiline Cultivars and Cultivar Mixtures for Disease Management. Annu Rev Phytopathol 40:381-410. https://doi.org/10.1146/annurev.phyto.40.011402.113723

50. Mundt CC, Sackett KE, Wallace LD (2011) Landscape heterogeneity and disease spread:

Experimental approaches with a plant pathogen. Ecol Appl 21:321-328. https://doi.org/10.1890/101004.1

51. Newton AC (2009) Plant Disease Control through the Use of Variety Mixtures. In: Disease Control in Crops: Biological and Environmentally Friendly Approaches. pp 162-171

52. Nicholls C, Altieri M (2004) Designing species-rich, pest-suppressive agroecosystems through habitat management. Agronomy 49-62

53. Papaïx J, Adamczyk-Chauvat K, Bouvier A, et al (2014a) Pathogen population dynamics in agricultural landscapes: The Ddal modelling framework. Infect Genet Evol 27:1-12. https://doi.org/10.1016/j.meegid.2014.01.022

54. Papaïx J, Touzeau S, Monod H, Lannou C (2014b) Can epidemic control be achieved by altering landscape connectivity in agricultural systems? Ecol Modell 284:35-47. https://doi.org/10.1016/j.ecolmodel.2014.04.014

55. Pariaud B, Ravigné V, Halkett F, et al (2009) Aggressiveness and its role in the adaptation of plant pathogens. Plant Pathol 58:409-424. https://doi.org/10.1111/j.1365-3059.2009.02039.x

56. Perfect SE, Green JR (2001) Infection structures of biotrophic and hemibiotrophic fungal plant pathogens. Mol Plant Pathol 2:101-108. https://doi.org/10.1046/j.1364-3703.2001.00055.x

57. Précigout P, Claessen D, Robert C (2017) Crop Fertilization Impacts Epidemics and Optimal Latent Period of Biotrophic Fungal Pathogens. Phytopathology PHYTO-01-17-001. https://doi.org/10.1094/PHYTO-01-17-0019-R 
58. Précigout PA, Claessen D, Makowski D, Robert C (2020a) Does the latent period of leaf fungal pathogens reflect their trophic type? A meta-analysis of biotrophs, hemibiotrophs, and necrotrophs. Phytopathology 110:345-361. https://doi.org/10.1094/PHYTO-04-19-0144-R

59. Précigout PA, Robert C, Claessen D (2020b) Adaptation of biotrophic leaf pathogens to fertilizationmediated changes in plant traits: A comparison of the optimization principle to invasion fitness. Phytopathology 110:1039-1048. https://doi.org/10.1094/PHYTO-08-19-0317-R

60. Rimbaud L, Papaïx J, Barrett LG, et al (2018a) Mosaics, mixtures, rotations or pyramiding: What is the optimal strategy to deploy major gene resistance? Evol Appl 11:1791-1810. https://doi.org/10.1111/eva.12681

61. Rimbaud L, Papaïx J, Rey JF, et al (2018b) Assessing the durability and efficiency of landscapebased strategies to deploy plant resistance to pathogens

62. Robert C, Bancal M-O, Ney B, Lannou C (2005) Wheat leaf photosynthesis loss due to leaf rust, with respect to lesion development and leaf nitrogen status. New Phytol 165:227-41. https://doi.org/10.1111/j.1469-8137.2004.01237.x

63. Robert C, Bancal M-O, Nicolas P, et al (2004) Analysis and modelling of effects of leaf rust and Septoria tritici blotch on wheat growth. J Exp Bot 55:1079-94. https://doi.org/10.1093/jxb/erh108

64. Robert C, Fournier C, Andrieu B, Ney B (2008) Coupling a 3D virtual wheat (Triticum aestivum) plant model with a Septoria tritici epidemic model (Septo3D): a new approach to investigate plantpathogen interactions linked to canopy architecture. Funct Plant Biol 35:997-1013

65. Robert C, Garin G, Abichou M, et al (2018) Plant architecture and foliar senescence impact the race between wheat growth and Zymoseptoria tritici epidemics. Ann Bot 121:975-989. https://doi.org/10.1093/aob/mcx192

66. Roelfs AP, Bushnell WR (1985) The Cereal Rusts

67. Sache I (2000) Short-distance dispersal of wheat rust spores by wind and rain Plant Genetics and Breeding. Agronomie 20:757-767. https://doi.org/10.1051/agro:2000102>

68. Saint-Jean S, Chelle M, Huber L (2004) Modelling water transfer by rain-splash in a 3D canopy using Monte Carlo integration. Agric For Meteorol 121:183-196. https://doi.org/10.1016/j.agrformet.2003.08.034

69. Saunders DGO, Pretorius ZA, Hovmøller MS (2019) Tackling the re-emergence of wheat stem rust in Western Europe. Commun Biol 2:9-11. https://doi.org/10.1038/s42003-019-0294-9

70. Skelsey P, Rossing WAH, Kessel GJT, van der Werf W (2010) Invasion of Phytophthora infestans at the landscape level: how do spatial scale and weather modulate the consequences of spatial heterogeneity in host resistance? Phytopathology 100:1146-1161. https://doi.org/10.1094/PHYTO06-09-0148

71. Suffert F, Delestre G, Gélisse S (2019) Sexual Reproduction in the Fungal Foliar Pathogen Zymoseptoria tritici Is Driven by Antagonistic Density Dependence Mechanisms. Microb Ecol 77:110-123. https://doi.org/10.1007/s00248-018-1211-3 
72. Suffert F, Sache I (2011) Relative importance of different types of inoculum to the establishment of Mycosphaerella graminicola in wheat crops in north-west Europe. Plant Pathol 60:878-889. https://doi.org/10.1111/j.1365-3059.2011.02455.x

73. van Maanen A, Xu XM (2003) Modelling Plant Disease Epidemics. Eur J Plant Pathol 109:669-682. https://doi.org/10.1023/A

74. Vidal T, Saint-Jean S, Lusley P, et al (2020) Cultivar mixture effects on disease and yield remain despite diversity in wheat height and earliness. Plant Pathol 69:1148-1160. https://doi.org/10.1111/ppa.13200

75. Walklate PJ (1989) Vertical dispersal of plant pathogens by splashing. Part I: the theoretical relationship between rainfall and upward rain splash. Plant Pathol 38:56-63. https://doi.org/10.1111/j.1365-3059.1989.tb01427.x

76. West JS, Townsend JA, Stevens M, Fitt BDL (2012) Comparative biology of different plant pathogens to estimate effects of climate change on crop diseases in Europe. Eur J Plant Pathol 133:315-331. https://doi.org/10.1007/s10658-011-9932-x

77. Xu X, Ma L, Hu X (2019) Overwintering of wheat stripe rust under field conditions in the northwestern regions of China. Plant Dis 103:638-644. https://doi.org/10.1094/PDIS-06-18-1053-RE

\section{Figures}

\section{$33 \%$ of wheat}

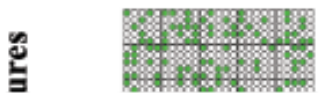

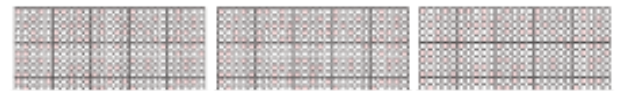

$67 \%$ of wheat
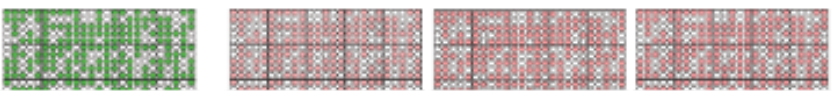


\section{Figure 1}

Simulations comparing the effect of crop diversification strategies (in rows: mixtures, mosaics, asynchronous and synchronous rotations) on WLR severity in landscapes comprising 33\% (left panel) and $67 \%$ (right panel) of the susceptible wheat. Levels of red correspond to disease intensity values measured as the area under disease progress curve (AUDPC) averaged over periods of three years. These results were obtained with the set of reference parameters for WLR (Table 1). Epidemiological equilibrium is reached after 8 years in these simulations, explaining why years 10 to 12 are not presented.

\section{Figure 2}

Effects of diversification strategies (intra-field crop mixtures, synchronous and asynchronous crop rotations, and landscape crop mosaics, and percentage of wheat in each of them) and weather conditions on the intensity of epidemics (AUDPC) of WLR (A-C) and STB (D-F). For WLR, favourable (A) and unfavourable (C) weather conditions lead to an early (800 dd after sowing) and late (1200 dd after sowing) onset of the epidemic respectively. For STB, the frequency of dispersing rains is the determining factor. The year 1994-95 (D) and 1996-97 (F) are considered respectively favourable and unfavourable for the development of the disease. An epidemic beginning at $1000 \mathrm{dd}$ post-sowing for WLR (B) and the time sequence 1994-2006 for STB (E) are considered as average weather conditions for both diseases (reference weather conditions in our simulations).

\section{Figure 3}

$<p>$ combined effect of diversification strategies (intra-field crop mixtures, synchronous and asynchronous crop rotations, and landscape crop mosaics, and percentage of wheat in each of them) and inoculum survival on the intensity of epidemics (AUDPC) of WLR and STB. Reference inoculum survival corresponds to <em>\&theta;</em> \&nbsp;= 0.01 for WLR and <em>\&theta;</em> \&nbsp;= 0.15 for STB. High inoculum survival corresponds to <em>\&theta; $</$ em $>\&$ nbsp; $=0.05$ for WLR and $<$ em>\&theta; $</$ em $>$ \&nbsp; $=0.5$ for STB. Low inoculum survival corresponds to <em $>\&$ theta; $</ e m>$ \&nbsp; $=0.005$ for WLR and $<$ em $>\&$ theta; $</$ em $>\&$ nbsp; $=0.015$ for STB. Note the scale differences on the $y$-axis. $</ p>$

\section{Supplementary Files}


This is a list of supplementary files associated with this preprint. Click to download.

- SupplementaryFig1.eps

- SupplementaryFig2.eps

- SupplementaryFig3.eps 